\title{
Assessment of Teaching Strategies Adopted for Effective Implementation of Science Subjects and Trade Modules Curriculum in Nigerian Technical Colleges
}

\author{
Yinusa Akintoye Faremi (Ph.D) \\ Department of Guidance and Counselling, Faculty of Education, Adekunle Ajasin \\ University, Akungba-Akoko, Ondo State, Nigeria \\ akintoyeyinusa@gmail.com
}

\section{Doi:10.5901/jesr.2014.v4n6p391}

\section{Abstract}

The study assessed the teaching strategies adopted for effective implementation of science subjects and trade modules' curriculum in Nigerian technical colleges. The purpose was to determine the effectiveness of the various teaching methods adopted for implementing the content of the science subjects and trade modules in Nigerian technical colleges. The study employed descriptive research design of survey type. The sample for the study consisted of 180 technical college science teachers and trade teachers selected from Ekiti, Ondo and Osun state technical colleges using multistage sampling technique. Teaching Strategies Rating Scale (TSRS) with reliability coefficient of 0.76 was used to collect necessary data. The data collected were analysed using descriptive and inferential statistics. The findings of the study revealed that projects are well selected and planned for the students and students are encouraged to always work on their own rather than group work. The group method, field trip and E-learning/ICT method are not always employed by science and trade teachers in imparting the content of the curriculum. It was concluded that the implementation of the content of technical education curriculum faces some set back due to the lecture method adopted by the teachers which made them to be more theoretical in their practice. It was recommended that the teaching strategies adopted for implementing the science subjects and trade modules in Technical Colleges should be revisited in line with the complexity of the content of the curriculum. The teachers should embark on the use of: group method, field trip method, project method and ICT method recommended for the teaching and learning of Science and trade subjects.

Keywords: Teaching Strategies, Implementation, Modular Curriculum, Skills, Science Teacher and Module Teacher

\section{Introduction}

Technical and Vocational Education helps in the acquisition of practical skills needed for self-reliance and national development. The aim of TVE is to make people to be creative and productive for a better living. The beneficiaries of TVE have the comparative advantage of being employable and employers of labour. The National Board for Technical Education (NBTE) modular curriculum on Vocational and Technical Education (VTE) that NABTEB made use, with the vision "to uphold the ideals of a free, united and egalitarian society and promote good quality technical and vocational education; a system that is flexible and accessible to all for the purpose of producing competent and relevant technological manpower needed for sustainable national development." While the mission of NBTE on vocational and technical education "is to promote the production of skilled/semi-skilled technical and professional manpower, to revitalize and sustain the national economy, reduce unemployment and poverty through the setting and maintenance of high standards, provision of current and reliable information for planning and decision making sourcing and disbursing of funds and adequate linkage with industry".

Curriculum implementation refers to what actually happens in practice as compared to what was supposed to happen. Curriculum implementation is the stage in which learning activities, teachers and learners are involved in negotiations aimed at promoting learning. The teacher adopts the appropriate teaching method and materials to guide students learning, the students on their own are actively involved in the process of interaction with learning activities.

The term teaching is defined as an occupation, an enterprise and an act of explaining, reading and writing (Suleiman and Nuhu, 2009 ). There are many teaching methods as practising teachers; quick meaning of this is that teaching methods have received different classifications from different teachers. In all fields and to all teachers, the most appropriate method of teaching therefore is that which can motivate the students and sustain their interest in the course of instruction. In terms of practical skill acquisition, it is that method which can bring the manufacturing process and exploration of materials into the classroom situation. Mills (1972) in Nneji (1997) says that teaching method itself is 
defined as the manner in which the content is presented to the learner. Among the already known traditional methods, some of them have been adopted to facilitate practical skill acquisition. Teaching methods also involves the interaction of the teachers, learners and the subject matter. Many different teaching methods can be adopted in technical education. The following methods below are appropriate when the acquisition of practical skill is needed. The teacher should select the method that is most appropriate for the topic or skill he wants to teach. Among the methods to be used and that are recommended by Olarewaju (1994), STAN (1999), Ajibade (2009), and Olokede and Olusanjo (2009) are:

(i) Demonstration (ii) Discussion (iii) Project (iv) Field- trip (v) Enquiry, (vi) Close Circuit Television (electronics learning) (vii) Discovery (viii) Problem Solving, (ix) Assignment and (x) Lecture Method.

Oranu (2001a) in a research carried out indicated that difficulties encountered during implementation of technical college curriculum included: lack of textbooks structured according to the modules; modules (Science Subjects) structured differently from already existing standard in higher institutions; and paucity of tools and equipment on the teaching of language. Students' command of English language is quite low to the extent that some teachers employ local languages to communicate with them.

The lecture and project methods are the main teaching/learning strategies employed in implementing the curriculum. In the main, the lecture method is content driven and certainly not child-centered. The teachers have to cover the content in order to ensure that students are able to pass the NABTEB examinations. Students are given ample opportunities to participate in the classroom instruction. The traditional method in which teaching reflects each discipline is still in use since the teacher has to concentrate on particular trade or modules (Oranu, 2001b).

The most important resource in the classroom is the teacher. A highly motivated and adequately trained teacher can rise above the constraining circumstance of poor material resources and government apathy. There is the need for teacher education to produce self-motivated teachers who will continually seek solutions to problems facing them in the classroom, who will not wait for government or external aid to implement change (Otuka, 2001). Omirin (2001) cited in Omirin (2004) stated that the quality of teachers is one important factor in the school system, which influences the performance of students.

McCaslin and Parks (2002) explained that preparation of technical education teachers in US, started with the beginning career and technical education, while facing the same expectation and demands required of all teachers. The teachers are also faced with the need to refine their pedagogical skills. Most beginning teachers are required to participate in teacher induction programmes designed to help them survive their first year of teaching and pass the praxis III (class-room performance assessment) examination, often teacher induction programmes are offered through cooperative efforts at local school districts, colleges and Universities, state department of education, professional career and technical education teachers' organizations.

The academic landscape in Nigeria includes the teaching and learning process, along with the educational programmes and courses and the pedagogy or methodology of teaching. Teaching involves research process which includes dissemination and publication; libraries and information services, including higher education administration and management (Beebe, 2004). Teachers and Instructors need to work together to decide how the curriculum will be used with students and the milestones that will be met at different points in the implementation process. Overtime, teachers need to be given different kinds of support, tailored to their changing needs. They also coach one another, conducting classroom visits to support both teachers and students during the teaching/learning process (Kluger-Bell \& Stern, 2006).

Ololube (2006) pointed out that teacher needs training not only in computer literacy but also in the application of various kinds of educational software in teaching and learning. Nigeria needs well qualified teachers that have gained pre-eminent knowledge in imparting vocational skill to the learners. Providing teachers with the necessary skills and knowledge needed to adequately carry out their teaching jobs as well as for professional growth. The teaching of Vocational Technical Education focuses on the psychomotor domain involves Motor Skill, Manipulation of materials, Objectives and acts that involve neuromuscular co-ordination and achievement of the psychomotor objective through which practical skill is acquired.

Nneji (1997) maintained that the teaching of practical skill involves active interface and interaction of materials process and product. Through practical skill activities, the world of work is highly stimulated. The success rate of practical skill acquisition is function of the methods of instruction. A good instructional method makes difficult subjects easy to learn while bad methods make even easy subject difficult to learn. Modular Curriculum comprises all trade modules which student must learn before graduation or being awarded the National Technical Certificate (NTC) and National Business Certificate (NBC) or Advance National Technical Certificate (ANTC) and Advance National Business Certificate (ANBT) which include trade like: Foundry Craft, Marine Engineering Craft, Ship Building Craft Practice, Computer Craft Studies, Animal Husbandry, Fisheries, Photographic Practice, Draughtmanship Craft Practice, Printing Craft Practice, 
Tourism, Salesmanship, Information and Communication Technology (ICT) etc. The basic science include subject like: Physics, Chemistry, Mathematics, Biology etc. In this study the teaching strategies to be examined are: (i) self selected technique, (ii) skills emphasized, (iii) teaching methods, and (iv) language of communication.

The purpose of the study is to examine the various strategies adopted by science and trade teachers in implementing technical college curriculum.

\section{Research Questions}

1. What are the self selected techniques adopted by science and trade teachers in technical colleges during implementation of the curriculum?

2. What are the skills emphasized by science and trade teachers in technical colleges during implementation of the curriculum?

3. What are teaching methods adopted by science and trade teachers in technical colleges during implementation of the curriculum?

4. What is the language of communication adopted by science and trade teachers in technical colleges during implementation of the curriculum?

\section{Research Hypothesis}

There is no significant difference between the teaching strategies adopted by science teachers and trade teachers in Technical Colleges during the implementation of the curriculum.

\section{Methodology}

The study employed descriptive research design of survey type. The population for the study consists of all the entire science and trade teachers in the approved technical colleges by National Business and Technical Examination Board (NABTEB) in South West, Nigeria. The sample for the study consisted of 180 science and trade teachers selected from the target population using Multistage Sampling Technique. In stage one, three states (Ekiti, Ondo and Osun) were selected using simple random technique. In stage two, five technical colleges were selected out of six in Ekiti state, five technical colleges out of six in Ondo State and Five out of nine in Osun State to make a total of fifteen technical colleges for the study. In stage three, 5 science teachers and 7 trade teachers were drawn from each technical college in the three states using proportional stratified sampling technique. The instrument titled Teaching Strategies Rating Scale (TSRS) with three point scales (Always=AL, Occasionally=OC and Never=NE the AL was rated with 3-point, OC with 2point and NE with 1-point) which was categorised into four sub-heading (self selected strategies, Skills emphasized during implementation, Teaching Methods and Language of Communication) used to collect necessary data from science teachers whose job is to teach the basic science like Physics, Chemistry, Mathematics, Biology etc and the trade module teachers whose job is to teach the theory and practical aspect of the trade modules in technical colleges. To ensure the validity of the instrument, the face and content validity were ascertained by evaluation expert, curriculum expert, and experienced science and trade teachers in two technical colleges in the one of the state in South West Nigeria that are not part of the sample for the study. The reliability of the instrument was ensured by administering copies of the questionnaire on the respondents that were not part of the sample for the study. Cronbach alpha was used to establish the consistency of the instrument with reliability coefficient of 0.76 . The TSRS was administered on the selected respondents by the researcher with the assistance of one trained research assistant. The data collected were analysed using descriptive and inferential statistics. The research questions raised were answered using descriptive statistics of frequency counts and percentage, while the hypothesis formulated was tested using t-test at 0.05 level of significance.

\section{Results}

\subsection{Research Question One}

What are the self selected techniques adopted by science and trade teachers in technical colleges during implementation of the curriculum? 
Table 1: Self selected Techniques

\begin{tabular}{|c|l|c|c|c|}
\hline S/N & \multicolumn{1}{|c|}{ Items } & AL (\%) & OC (\%) & NE (\%) \\
\hline 1 & Projects were carefully selected and planned for the students. & $100(55.6)$ & $60(33.3)$ & $20(11.1)$ \\
\hline 2 & Students were encouraged to always work on their own rather than group work. & $100(55.6)$ & $55(30.5)$ & $25(13.9)$ \\
\hline 3 & Students were referred to text books for home works and assignment. & $70(38.9)$ & $96(53.3)$ & $14(1.8)$ \\
\hline 4 & $\begin{array}{l}\text { Postponing some activities during the teaching and learning process to allow } \\
\text { students read their textbooks in the class for better understanding. }\end{array}$ & $30(16.7)$ & $94(52.2)$ & $56(31.1)$ \\
\hline
\end{tabular}

It was observed in table 1 that the science and trade teachers that implemented the content of the modular curriculum obviously indicate that the following techniques were selected during the implementation stage of the curriculum: projects were carefully selected and planned for the students (55.6\%) and students were encouraged to always work on their own rather than group work (55.6\%). Studentswere referred to textbooks for home work and assignment occasionally, and postpone some activities during the teaching and learning process to allow students read their textbooks in the class for better understanding.

\subsection{Research Question Two}

What are the skills emphasized by science and trade teachers in technical colleges during implementation of the curriculum?

Table 2: Skills emphasized during implementation

\begin{tabular}{|c|c|c|c|c|}
\hline $\mathrm{S} / \mathrm{N}$ & Items & $\mathrm{AL}(\%)$ & OC $(\%)$ & NE (\%) \\
\hline 5 & To what extent are the following skills emphasized in the teaching of the new trade modules? & & & \\
\hline a & 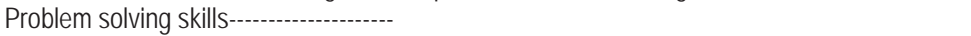 & 120(66.7) & $40(22.0)$ & 20(11.1) \\
\hline b & Information skills------------------------- & 122(67.8) & $48(26.6)$ & $10(5.6)$ \\
\hline c & 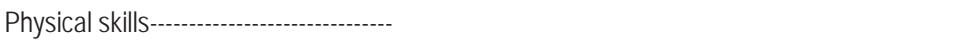 & $106(64.0)$ & $54(26.6)$ & $10(5.6)$ \\
\hline$d$ & Communication skills-------------------- & $120(66.6)$ & $48(26.6)$ & $12(6.6)$ \\
\hline e & Social and cooperative skills.--------- & $100(55.6)$ & $64(35.0)$ & $16(8.9)$ \\
\hline
\end{tabular}

It was observed in table 2 that the following skills were always emphasized: problem solving skills (66.7\%), information skills (61.1\%), physical skills (64\%), communication skills (66.6\%) and social and cooperative skills (55.6\%).

\subsection{Research Question Three}

What are teaching methods adopted by science and trade teachers in technical colleges during implementation of the curriculum?

Table 3: Teaching Methods

\begin{tabular}{|c|c|c|c|c|}
\hline $\mathrm{S} / \mathrm{N}$ & Items & $\mathrm{AL}(\%)$ & OC (\%) & NE (\%) \\
\hline $\begin{array}{l}6 \\
a \\
b \\
c \\
d \\
e \\
f \\
g\end{array}$ & 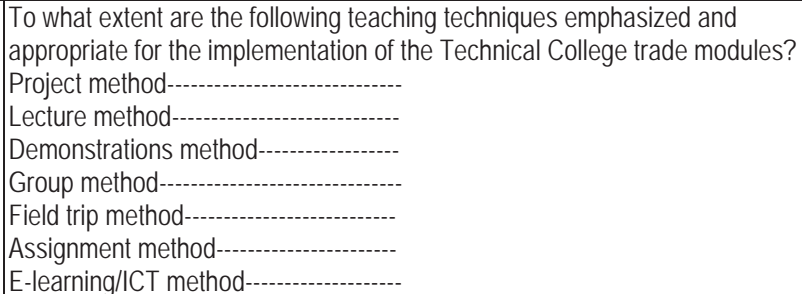 & $\begin{array}{c}102(56.7) \\
136(75.6) \\
124(68.9) \\
66(36.7) \\
44(24.4) \\
104(57.8) \\
60(33.3)\end{array}$ & \begin{tabular}{|c|}
$66(36.7)$ \\
$26(14.4)$ \\
$46(25.6)$ \\
$100(56.6)$ \\
$106(58.9)$ \\
$62(34.0)$ \\
$74(41.1)$
\end{tabular} & $\begin{array}{c}12(6.6) \\
18(10.0) \\
10(5.5) \\
14(7.8) \\
10(5.0) \\
14(7.8) \\
46(25.6)\end{array}$ \\
\hline
\end{tabular}

It was observed in table 3 that the following teaching methods were highly used by the science and trade teachers: project method (56.7\%), lecture method (75.6\%), Demonstration method (68.9\%) and Assignment method (57.8\%). It was also observed that the science and trade teachers made use of group method, field trip method and e-learning method occasionally. 


\subsection{Research Question Four}

What is the language of communication adopted by science and trade teachers in technical colleges during implementation of the curriculum?

Table 4: Language of Communication

\begin{tabular}{|c|l|c|c|c|}
\hline S/N & \multicolumn{1}{|c|}{ OC (\%) } & NE (\%) \\
\hline 7 & To what extent are the following languages of instruction effective during implementation? & & & \\
a & Teachers rely heavily on a traditional grammar approach as a medium of communication. & $44(24.4)$ & $100(55.6)$ & $36(20.0)$ \\
b & $\begin{array}{l}\text { The use of developed Nigeria languages as co-official language with English as a medium } \\
\text { of instruction. }\end{array}$ & $60(33.3)$ & $86(47.7)$ & $34(18.9)$ \\
c & English language. & $100(55.6)$ & $50(27.8)$ & $30(16.6)$ \\
\hline
\end{tabular}

It was revealed in table 4 that the English Language (55.6\%) is the most used language for communication during implementation. It was also revealed that the science and trade teachers made use of traditional grammar and developed Nigeria language as co-official language with English as a medium of instruction occasionally.

Hypothesis: There is no significant difference between the teaching strategies adopted by science teachers and trade teachers in Technical Colleges during the implementation of the curriculum.

Table 4: t-test on the Teaching Strategies Adopted for Implementing the Curriculum

\begin{tabular}{|l|c|c|c|c|c|c|c|}
\hline Source & $\mathrm{N}$ & Mean () & S.D & Df & t-cal & t-crit & Remark \\
\hline Science Teachers & 75 & 26.632 & -1.335 & \multirow{2}{*}{178} & \multirow{2}{*}{1.372} & \multirow{2}{*}{1.960} & \multirow{2}{*}{ NS } \\
\hline Trade Teachers & 105 & 27.269 & 2.369 & & & & \\
\hline
\end{tabular}

NS = Not significant $(P>0.05)$

Table 4 showed that ( $t_{c a l}=1.372, P>0.05$ level of significance) the null hypothesis is accepted. Therefore, there is no significant difference between the teaching strategies adopted by the science and trade teachers in implementing the content of the modular curriculum for Technical Colleges.

\section{Discussion}

The study showed that projects are well selected and planned for the students and students are encouraged to always work on their own rather than group work. The findings showed that students are referred to text books occasionally for assignment and postponing some activities during the teaching/learning process to allow students read their textbooks in the classroom for better understanding. The study revealed the skills emphasised by the teachers during the teaching learning process. It was found that the teachers emphasized the problem solving skills, information skills, physical skills, communication skills and social skills during the teaching-learning process. The study revealed the teaching methods adopted in teaching the content of the modular curriculum for technical colleges. Methods like group method, field trip and E-learning/ICT are not frequently used by the science and trade teachers when compared with other methods like demonstration, lecture and assignment methods. Oranu (2001b) proved that lecture method is content driven and certainly not child centered. Marinho (2009) pointed out that teacher-centered method of teaching does little to advance conceptual understanding and critical thinking. Ajibade (2009) stated that instructional methods are means of effective teaching; it is also the basic and broad process in which knowledge, content, concept, skills, value and attitude are inculcated to the students in teaching situation. The study also revealed that the teachers employed the use of English Language when compared with Nigeria developed language and traditional language.

The findings equally showed that there was no significant difference between the teaching strategies adopted by the science and trade teachers in implementing the content of the curriculum for Technical Colleges. The study confirmed that both the science and trade teachers adopted the same teaching strategies in impacting knowledge on to the students in science subjects and trade modules. The fact has been recognized that no matter how well meaning and genuine the objectives and contents of any curriculum may be, the extent to which the curriculum can succeed will depend on the functioning of the methods adopted in implementing the curriculum and no method can stay in isolation. These findings are in agreement with that of Suleiman and Nuhu (2009) that demonstration method enables learners to maintain and develop their interest, new skills and abilities in doing new things in life. Suleiman and Nuhu (2009) stressed further that good teaching methods create creativity, constructive and critical thinking in learners lead to innovation in education. Adegbite, Adams and Oduntan (2007) stressed that project method draw a range of skills and 
develop students' creativity. Dantani and Shehu (2009) pointed out that for a society to advance, by implication, required the triangulation of Science, Technology and Mathematic (STM) contents in its teaching and learning processes.

\section{Conclusion}

The findings of this study revealed that the science and trade teachers made use of multivariate teaching strategies during the implementation of the content of technical college curriculum. The lecture method made used by the science and trade teachers made them to be more theoretical when discharging their duties. The Group, field trip and Elearning/ICT method made use occasionally by the teachers have implications on the teaching and learning of science subjects and trade modules in technical colleges. The teaching strategies for implementing the content of science subjects and trade modules curriculum should be revisited in line with the complexity of the content of the curriculum.

\section{Recommendations}

The government (ministry of education) should organise a seminal and workshop to educate teachers, parents and students on the usefulness of field trip and how the stakeholders can embark on it and adopt it as one of the methods of imparting knowledge. Instructional and communication method recommended for science, technical and vocational education should be improved upon such as Information and Communication Technology (ICT), computer, Internet service etc so that students can develop and acquire the technical skills and core skills that will make them survive in their immediate environment.

\section{References}

Adegbile, J. A., Adams, O. U., \& Oduntan, F. M. (2007). School-based assessment as corrective measure for early childhood learning. National Association of Evaluators and Researcher, $9^{\text {th }}$ National conference proceeding, 22-27.

Ajibade, A. (2009). Understanding micro teaching theory and practice. Osogbo:Simba Ventures.

Beebe, M. A. (2004). Impact of ICT revolution on the African academic landscape. CODESRIA Conference on Electronic Publishing and Dissemination" Daka Senegal 1-2 September. Retrieved August 22, 2008, from www.codesria.org/limits/conference /e/publ/beebe

Dantani, I. \& Shehu, U. (2009). Problems of teaching science and technology and mathematics (STM): (A study of rural secondary schools in Sokoto state). Sokoto Educational Review. 11 (2), 156-164.

Kluger-Bell, B. and Stern, F. (2006). Curriculum implementation issues and challenges. Retrieved August 22, 2008, from http://www. Weblogyod.com/2006/teacher

Marinho, S. (2009). An analysis of curriculum development and content delivery in Nigeria. Retrieved June 11, 2011, from quanesis.com/nigcurriculum

McCaslin, N.L. and Parks, D. (2002). Teacher education in career and technical education. Background and policy implication for the new millennium columbus. Ohio State

University. The National Disseminations Centre for Career and Technical Education.

Nneji, N. G. (1997). Understanding, teaching and evaluating skill acquisition. A Journal of School of Technical Education (Technical) Akoka, Lagos. 1 (1).

Olarewaju, A. O. (1994). New approaches to the teaching of integrated science. Ibadan: Alafas Nigeria Company.

Olokede, N. O. And Olusanjo, M. O. (2009). Introduction to principles and method of teaching (2nd ed.). Abuja: Akitol prints.

Ololube, N.P. (2006). Appraising the relationship between ICT usage and integration and the standard of teacher education programs in a developing economy. International Journal of Education and Development Using Information and Communication Technology (IJEDICT) 20062 (3): 70-85

Otuka, J. O (2001). Strategies for introducing new curricula in West Africa innovative ideas and techniques for science, technology and mathematics education in Africa. Retrieved August 19, 2008, from htt://www.wkap. Nl/journal/prospect. 13-18

Omirin, M. S. (2004). Issues in the implementation of continuous assessment in Ekiti State secondary schools. Nigerian Journal of Counselling and Applied Psychology. 2 (1), 177- 185.

Oranu, R. N. (2001a). Strategies for introducing new curriculum in West Africa: Vocational and technical education. Retrieved August 22, 2008, from http://www.wkap .Nl.journal /prospect. 18-21

Oranu, R.N. (2001b): Strategies for introducing new curriculum in West Africa: Strategies for teachers coping with the new curriculum. Retrieved August 22, 2008, from www.wkap.NI/journal/prospect. 23-25.

Oviawe, J. I. (2009). The role of technical and vocational education in youth empowerment and poverty alleviation. Sokoto Educational Review, 11 (2).

Science Teacher Association of Nigeria (STAN) (1999). Nigeria integrated science project. Ibadan: Heinemann Educational book (Nigeria) plc.

Suleiman, L. And Nuhu. J. I. (2009). Teachers and teaching methods: The effects on learning for sustainable development. Sokoto Educational Review, 11 (2), 131-139. 